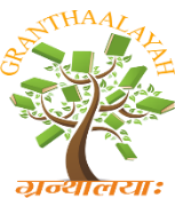

\author{
INTERNATIONAL JOURNAL OF RESEARCH - \\ GRANTHAALAYAH \\ A knowledge Repository
}

Social

\title{
INFLUENCES OF TWO COMBINATIONS OF NEUROMUSCULAR DRILLS AND ASANA PRACTICES ON AGILITY OF BASKETBALL PLAYERS
}

\author{
Dr. D. Maniazhagu ${ }^{1}$, S. Malar ${ }^{2}$, M. Murali ${ }^{3}$ \\ ${ }^{1}$ Assistant Professor, Department of Physical Education and Health Sciences, Alagappa \\ University, Karaikudi, India \\ ${ }^{2}$ (UGC-NET-SRF), Research Scholar, Department of Physical Education and Health Sciences, \\ Alagappa University, Karaikudi, India \\ ${ }^{3}$ M. Phil Scholar (SSP) Department of Physical Education and Health Sciences, Alagappa \\ University, Karaikudi, India
}

\begin{abstract}
The purpose of study was to find out the influences of two combinations of neuromuscular drills and asana practices on agility of basketball players. To achieve the purpose of the study, thirty basket ball players with the age of 10 to 13 years from Navabisha Montessori School, Velachery, Chennai, Tamilnadu were selected as subject at random. The study was formulated as pre and post test random group design. The selected subject was divided into three equal groups. The group-1 $(\mathrm{n}=10, \mathrm{NMD}-\mathrm{AP})$ underwent neuromuscular drills combined with asana practices. The group-2 $(\mathrm{n}=10$, AP-NMD) underwent asana practices combined with neuromuscular drills and group 3 served as control group $(\mathrm{n}=10, \mathrm{CG})$. In this study, two training programme were adopted as independent variables and the agility was selected as dependent variable. It was tested by T test; scores recorded in seconds. The agility tested before and after the training period. The collected pre and post data was critically analyzed with apt statistical tool of analysis of co-variance (ANCOVA). The Scheffe's post hoc test was used to find out pair-wise comparisons between groups. The result clearly proved that there was a significant improvement on agility in experimental groups than the control group.
\end{abstract}

Keywords: Neuromuscular; Asana; Agility; Basketball; ANCOVA.

Cite This Article: Dr. D. Maniazhagu, S. Malar, and M. Murali. (2019). "INFLUENCES OF TWO COMBINATIONS OF NEUROMUSCULAR DRILLS AND ASANA PRACTICES ON AGILITY OF BASKETBALL PLAYERS." International Journal of Research - Granthaalayah, 7(7), 167-172. https://doi.org/10.29121/granthaalayah.v7.i7.2019.743.

\section{Introduction}

Basketball skills, such as shooting, passing, dribbling and rebounding along with offensive and defensive teamwork are pre requisites for successful participation in the sport. (Jon A. Oliver, 
2003) Basketball has gained worldwide popularity and fascinated players and spectators with its dynamic characteristics as a team sport (Hoffman\& Maresh, 2000) In this sport, players cover about 4500-5000 m during a 40-min game with a variety of multidirectional movements such as running, dribbling, and shuffling at variable velocities In order to execute running, dribbling and shuffling like movements during performance, both aerobic and anaerobic metabolic systems appear to be involved throughout a game. (Ciuti et al., 1996)

Agility is an important capacity for many elite performers to develop. Agile movements of the body can be used to great effect to free an offensive player from the opposition. In case in which the player needs to change direction quickly in sidestepping and cutting, it is important to move the body's centre of mass away from the base of support very quickly. Therefore, agility appears quite different to dynamic balance; however, it is important to remember that the later relies on the capacity to have subsequent movements planed to ensure the continued maintenance of balance. (Timothy R. Ackland, Bruce Elliott, John Bloomfield, 2009) The importance of both speed and agility for determining the success of an athlete or team is well acknowledged among coaches of anaerobic sports such as football, basketball or hockey. (Jay Hoffman, 2002) Hence this study an attempt was made to find out influences of two combinations of neuromuscular drills and asana practices on agility of basketball players.

\section{Methods and Tolls}

The selected two treatment group's was performed five days in a week for the period of six weeks, as per the stipulated training program. The training intervention group undergone their respective training as per the below schedule under the supervision of the researcher who provided motivation, advice and encouragement to the students. Each day the training schedule was conducted only in the evening session that lasted for sixty minutes. Prior to and after every training session subject of experimental group had the ten minutes of warm-up and ten minutes of warm down exercise involving jogging, mobility and stretching exercise.

\section{Training Schedule for group-1- Neuromuscular drills combined with asana practice Neuromuscular drills}

The following SAQ drills used for this purpose,

1) Standing stationary arm swing

2) Ladder Speed Run

3) Running Balance

4) Run Through

5) Crossover skipping

6) T-Drill

\begin{tabular}{|l|l|l|l|l|l|}
\hline Activity & Weeks & Rep & Sets & Rec- in bet Exr. & Rec- in between sets \\
\hline SAQ Drills & 1-2 weeks & Each 30 sec & 3 & $1 \mathrm{~min}$ & $3 \mathrm{~min}$ \\
\hline SAQ Drills & 3-4 weeks & Each 45 sec & 3 & $1 \mathrm{~min}$ & $3 \mathrm{~min}$ \\
\hline SAQ Drills & $5-6$ weeks & Each 60 sec & 3 & $1 \mathrm{~min}$ & $3 \mathrm{~min}$ \\
\hline
\end{tabular}




\section{Asana Practices}

The following asanas used for the propose,

1) Suryanamaskar (12steps)

2) Pachimottasana

3) Vajrasana

4) Danurasana

5) Navasana

6) Bhujangasana

\begin{tabular}{|l|l|l|l|l|}
\hline Activity & Weeks & Duration & Sets & Rec- in between sets \\
\hline Suryanamaskar (12steps) & $\mathbf{1 - 6}$ weeks & $3 \mathrm{~min}$ & 2 & $2 \mathrm{~min}$ \\
\hline Asanas & $\mathbf{1 - 2}$ weeks & Each $15 \mathrm{sec}$ & 3 & $3 \mathrm{~min}$ \\
\hline Asanas & $\mathbf{3 - 4}$ Weeks & Each $30 \mathrm{sec}$ & 3 & $3 \mathrm{~min}$ \\
\hline Asanas & $\mathbf{5 - 6}$ weeks & Each $45 \mathrm{sec}$ & 3 & $3 \mathrm{~min}$ \\
\hline
\end{tabular}

Training Schedule for group-2-Asana Practice combined with SAQ Drills

\section{Asana Practices}

The following asanas used for the propose,

1) Suryanamaskar (12steps)

2) Pachimottasana

3) Vajrasana

4) Danurasana

5) Navasana

6) Bhujangasana

\begin{tabular}{|l|l|l|l|l|}
\hline Activity & Weeks & Duration & Sets & Rec- in between sets \\
\hline Suryanamaskar (12steps) & $\mathbf{1 - 6}$ weeks & $3 \mathrm{~min}$ & 2 & $2 \mathrm{~min}$ \\
\hline Asanas & $\mathbf{1 - 2}$ weeks & Each $15 \mathrm{sec}$ & 3 & $3 \mathrm{~min}$ \\
\hline Asanas & $\mathbf{3 - 4}$ Weeks & Each $30 \mathrm{sec}$ & 3 & $3 \mathrm{~min}$ \\
\hline Asanas & $\mathbf{5 - 6}$ weeks & Each $45 \mathrm{sec}$ & 3 & $3 \mathrm{~min}$ \\
\hline
\end{tabular}

\section{Neuromuscular drills}

The following SAQ drills used for this purpose,

1) Standing stationary arm swing

2) Ladder Speed Run

3) Running Balance

4) Run Through

5) Crossover skipping

6) T-Drill

\begin{tabular}{|l|l|l|l|l|l|}
\hline Activity & Weeks & Rep & Sets & Rec- in bet Exr. & Rec- in between sets \\
\hline SAQ Drills & 1-2 weeks & Each 30 sec & 3 & $1 \mathrm{~min}$ & $3 \mathrm{~min}$ \\
\hline SAQ Drills & 3-4 weeks & Each 45 sec & 3 & $1 \mathrm{~min}$ & $3 \mathrm{~min}$ \\
\hline SAQ Drills & $5-6$ weeks & Each 60 sec & 3 & $1 \mathrm{~min}$ & $3 \mathrm{~min}$ \\
\hline
\end{tabular}


Table 1: The Results of Analysis of Covariance on Agility of Different Groups (Scores in Seconds)

\begin{tabular}{|c|c|c|c|c|c|c|c|c|c|}
\hline \multicolumn{2}{|l|}{ Test Conditions } & G-1 & G- 2 & G- 3 CG & SV & SS & Df & MS & 'F' Ratio \\
\hline \multirow[t]{2}{*}{ Pre } & $\mathrm{M}$ & 13.43 & 13.4 & 13.44 & $\mathrm{~B}$ & 0.006 & 2 & 0.003 & \multirow[t]{2}{*}{0.03} \\
\hline & S.D. & 0.31 & 0.27 & 0.36 & $\mathrm{~W}$ & 2.74 & 27 & 0.1 & \\
\hline \multirow[t]{2}{*}{ Post test } & $\mathrm{M}$ & 12.60 & 12.66 & 13.68 & B & 7.29 & 2 & 3.65 & \multirow[t]{2}{*}{$44.86^{*}$} \\
\hline & S.D. & 0.28 & 0.3 & 0.27 & $\mathrm{~W}$ & 2.19 & 27 & 0.8 & \\
\hline \multirow[t]{2}{*}{ Adjusted post test } & $\mathrm{M}$ & 12.59 & 12.67 & 13.67 & B & 7.19 & 2 & 3.59 & \multirow[t]{2}{*}{$61.68^{*}$} \\
\hline & & & & & $\mathrm{W}$ & 1.51 & 26 & 0.06 & \\
\hline
\end{tabular}

* Significant at .05 level of confidence. The required tables value for test the significance was 3.35 and 3.37with the df of 2 and 27, 2 and 26.

The pre test mean and standard deviation on agility scores G1, G2 and G3 were $13.43 \pm 0.31$, $13.4 \pm 0.27$ and $13.44 \pm 0.36$ respectively. The obtained pre test $F$ value of 0.03 was lesser than the required table $\mathrm{F}$ value 3.35 . Hence the pre test means value of neuromuscular drills combined with asana practices, asana practices combined with neuromuscular drills and control group on agility before start of the respective treatments were found to be insignificant at 0.05 level of confidence for the degrees of freedom 2 and 27. Thus this analysis confirmed that the random assignment of subjects into three groups were successful. The post test mean and standard deviation on agility of G1, G2 and G3 were $12.60 \pm 0.28,12.66 \pm 0.3$ and $13.68 \pm 0.27$ respectively. The obtained post test $\mathrm{F}$ value of 44.86 was higher than the required table $\mathrm{F}$ value of 3.35 . Hence the post test means value of neuromuscular drills combined with asana practices and asana practices combined with neuromuscular drills on agility were found to be significant at 0.05 level of confidence for the degrees of freedom 2 and 27 . The results proved that the selected two training interventions namely neuromuscular drills combined with asana practices and asana practices combined with neuromuscular drills was produced significant improvement rather than the control group of the sample populations. The adjusted post test means on agility scores of G1, G2 and G3 were 12.59, 12.67and 13.67 respectively. The obtained adjusted post test $F$ value of 61.68 was higher than the required table $\mathrm{F}$ value of 3.37. Hence the adjusted post test means value of neuromuscular drills combined with asana practices and asana practices combined with neuromuscular drills on agility were found to be significant at 0.05 level of confidence for the degrees of freedom 2 and 26 . The results confirm that the selected two training interventions namely neuromuscular drills combined with asana practices and asana practices combined with neuromuscular drills on agility was produced significant difference among the groups.

Table 1 (A): The Results of scheffe's post hoc test mean differences on AGILITY among Three Groups (Scores in Seconds)

\begin{tabular}{|l|l|l|l|l|}
\hline G- 1 NMD-AP & G- 2 AP-NMD & G- 3 CG & Mean Differences & Confidence Interval Value \\
\hline 12.59 & 12.67 & & 0.08 & 0.35 \\
\hline 12.59 & & 13.67 & $1.08^{*}$ & 0.35 \\
\hline & 12.67 & 13.67 & $0.99^{*}$ & 0.35 \\
\hline
\end{tabular}

* Significant at .05 level of confidence. 


\section{Result of Scheffe's Post Hoc Test on Agility}

Table I (a) shows the paired mean differences of neuromuscular drills combined with asana practices, asana practices combined with neuromuscular drills and control group on agility. The pair wise comparisons results as follows. First comparison: Group 1 and Group 2: The pair wise mean difference of group 1 and group 2 values 0.08 was lesser than the confidential interval value of 0.35 . Hence the first comparison was insignificant. The results of this comparison clearly proved that both training have produced similar effects on agility. Second comparison: Group 1 and Group 3: The pair wise mean difference of group 1 and group 3 values 1.08 was higher than the confidential interval value of 0.35 . Hence the second comparison was significant. The results of this comparison clearly proved that neuromuscular drills combined with asana practices have produced greater improvements on agility, than the control group. Third comparison: Group 2 and Group 3: The pair wise mean difference of group 2 and group 3 values 0.99 was higher than the confidential interval value of 0.35 . Hence the third comparison was significant. The results of this comparison clearly proved that asana practices combined with neuromuscular drills have produced greater improvements on agility, than the control group.

The adjusted post test mean deference of experimental and control group value graphically represented in the figure-1

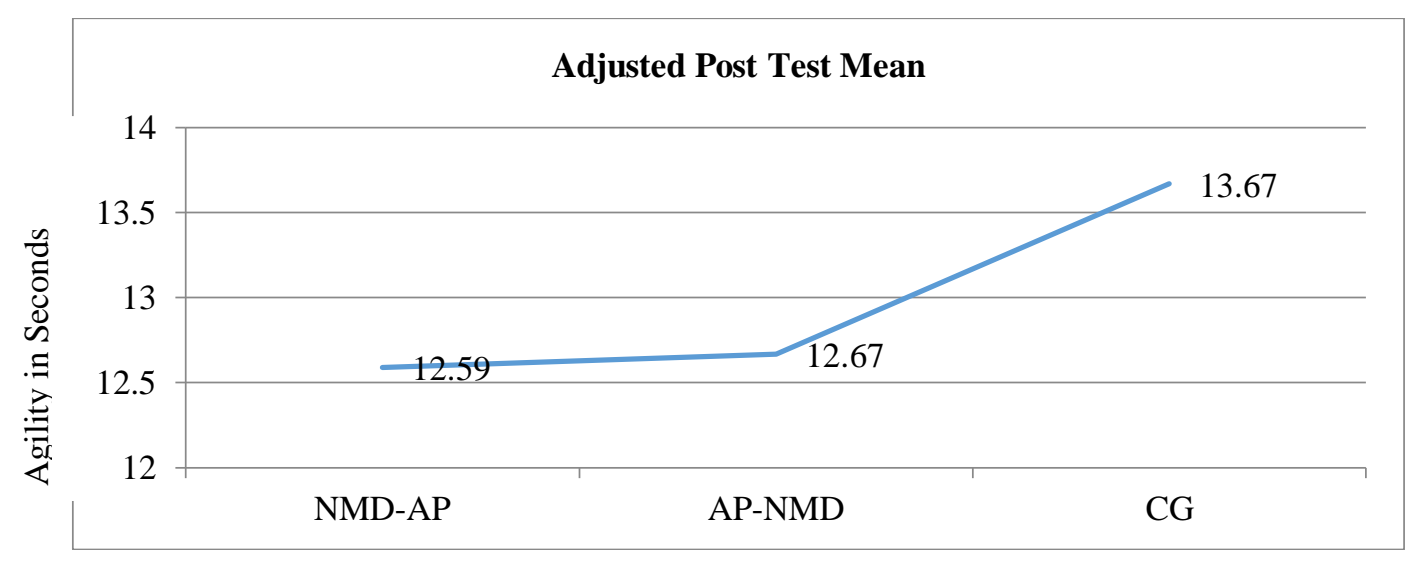

Figure 1

\section{Discussion}

After analyzing the statistical end results the researcher found that the selected training groups have significantly improved the performance of agility from the base line to post interventions. The pre to post intervention was present as follows. The neuromuscular drills combined with asana practices group from pre $(13.43 \pm 0.31)$ to post $(12.60 \pm 0.28)$ and asana practices combined with neuromuscular drills from pre $(13.4 \pm 0.27)$ to post $(12.66 \pm 0.3)$. The percentage of improvement on agility for neuromuscular drills combined with asana practices group was $0.008 \%$ and asana practices combined with neuromuscular drills group was $0.007 \%$. The findings support, in line with the result of the following studies. The study findings from effects of a plyometric and strength training program on the fitness performance in young basketball players demonstrated that a short-term plyometric and strength training program significantly increases motor 
performance skills in young basketball players. (Ognjen Andrejić, 2012). In another study, effects of a short term plyometric training program of agility in young basketball players revealed that the benefits of short term plyometric training program of agility in young basketball players. (Baljinder Singh Bal, Parminder Jeet Kaur, Davinder Singh, 2011)

\section{Conclusion}

The neuromuscular drills combined with asana practices and asana practices combined with neuromuscular drills have improved the performance of agility than the control group. The neuromuscular drills combined with asana practices and asana practices combined with neuromuscular drills produced similar effects on agility. The control group did not show any improvement.

\section{Acknowledgements}

Dr. D. Maniazhagu thank for the financial support of MHRD-UGC, RUSA-Phase 2.0 grant No. F,24-5/2014-U, Policy (TN Multi-Gen), Dept. of. Edn. Government of India, dt 09.10.2018

\section{References}

[1] Baljinder Singh Bal, Parminder Jeet Kaur, Davinder Singh, (2011). "Effects of a short term plyometric training program of agility in young basketball players". Brazilian Journal of Biomotricity

[2] Ciuti C, Marcello C, Macis A, Onnis E, Solinas R, Lai C, Concu A. Improved aerobic power by detraining in basketball players mainly trained for strength. Sports Med Training Rehab 1996: 6: 325-335.

[3] Hoffman JR, Maresh CM. Physiology of basketball. In: Garrett WE Jr, Kirkendall DT, eds. Exercise and sport science. Philadelphia, PA: Lippincott Williams \& Wilkins, 2000: 733-744.

[4] Jay Hoffman. (2002) Physiological Aspects of Sport Training and Performance. Human kinetics. P. No:98

[5] Jon A. Oliver., 2003. "Basketball Fundamentals". Human kinetics. P.No: 6

[6] Ognjen Andrejić, (2012). "The effects of a plyometric and strength training program on the fitness performance in young basketball players". FACTA UNIVERSITATIS Series: Physical Education and Sport Vol. 10, No 3, 2012, pp. 221 - 229

[7] Timothy R. Ackland, Bruce Elliott, John Bloomfield (2009). "Applied Anatomy and Biomechanics in Sport”. Human kinetics. P. No:2

\footnotetext{
*Corresponding author.

E-mail address: drmaniazhagu@ gmail.com
} 